\title{
GEOGRAFIA E POVOS INDÍGENAS NO BRASIL: UMA ANÁLISE A PARTIR DOS DOCUMENTOS NORMATIVOS DA EDUCAÇÃO ESCOLAR INDÍGENA
}

\author{
Elson Mateus Monteiro Sousa \\ Mestrando do Programa de Pós-Graduação em Geografia (PPGG/UEPA) \\ Bolsista da Fundação Amazônia Paraense de Amparo a Estudos e Pesquisas (FAPESPA) \\ Belém, PA, Brasil. \\ elsont2015@gmail.com \\ Adolfo da Costa Oliveira Neto \\ Doutor em Geografia \\ Professor do Programa de Pós-Graduação em Geografia (PPGEO/UFPA e PPGG/UEPA) \\ Belém, PA, Brasil. \\ adolfoneto@ufpa.br
}

\begin{abstract}
RESUMO
O presente artigo tem como objetivo compreender como a geografia tem sido incluída nos documentos normativos da educação escolar indígena. Prioriza-se, na análise aqui desenvolvida, o recorte histórico pós-1988, quando emerge o modelo intercultural-bilíngue, que tem se consolidado nas recentes décadas dentro da agenda dos movimentos indígenas no Brasil. Metodologicamente, parte-se de uma abordagem de estudo quantitativa e qualitativa com pesquisa documental e revisão bibliométrica, culminando na análise dos principais documentos desta modalidade de educação. De acordo com a análise efetuada, a geografia, no atual modelo intercultural, tem sido caracterizada por um forte apelo aos conceitos de território e territorialidade, bem como na utilização da cartografia como um eixo transversal da geografia nesta modalidade de educação, conforme previsto no Referencial Curricular Nacional para as Escolas Indígenas (RCNEI).
\end{abstract}

Palavras-chave: Tópicos Especiais de Educação. Políticas Indigenistas. Território. Amazônia.

\section{GEOGRAPHY AND INDIGENOUS PEOPLES IN BRAZIL: AN ANALYSIS FROM THE NORMATIVE DOCUMENTS OF INDIGENOUS SCHOOL EDUCATION}

\begin{abstract}
This article aims to understand how geography has been included in the normative documents of indigenous school education. Priority is given to the post-1988 historical profile, when the intercultural-bilingual model emerges, which has been consolidated in recent decades within the agenda of indigenous movements in Brazil. Methodologically, it starts with a quantitative and qualitative study approach with documentary research and bibliometric review, culminating in the analysis of the main documents of this type of education. According to the analysis carried out, geography, in the current intercultural model, has been characterized by a strong appeal to the concepts of territory and territoriality, as well as in the use of cartography as a transversal axis of geography in this modality of education, as foreseen in the National Curriculum Reference for Indigenous Schools (RCNEI).
\end{abstract}

Keywords: Special Education Topics. Indigenous policies. Territory. Amazon.

\section{INTRODUÇÃO}

Os povos indígenas, detentores de sistemas de conhecimentos milenares, possuem também seus próprios modos de reprodução e difusão de saberes. A estes sistemas de reprodução do conhecimento, Meliá (1979) denominou de educação indígena, mediante a qual a cultura destes povos tende a se reproduzir nas novas gerações.

No processo histórico de colonização do continente americano pelos europeus, um dos pilares no controle dos povos indígenas foi a implementação da instituição escolar pelos colonizadores estrangeiros. Tal instituição possuía como objetivo principal a catequização missionária das

$\begin{array}{llll}\text { Caminhos de Geografia } \quad \text { Uberlândia-MG } & \text { v. 21, n. 78 } \quad \text { Dez/2020 } & \text { p. 78-92 Página } 78\end{array}$


comunidades, caracterizando, portanto, um modelo escolar assimilacionista. Assim, os povos originários se depararam com dois sistemas distintos de educação: a educação indígena e a educação escolar indígena (LUCIANO, 2011).

Com o fortalecimento do movimento indígena, organizado por meio de associações em diversas esferas e áreas de atuação, o modelo de educação escolar indígena começou a ser repensado, o que se efetivou com a Constituição Federal de 1988 e a Lei de Diretrizes e Bases da Educação, de 1996. É neste contexto que desponta um novo modelo de educação escolar indígena, alicerçado na interculturalidade, no bi-multilinguismo, na educação diferenciada e específica.

O modelo intercultural-bilíngue tem se consolidado nas recentes décadas dentro da agenda dos movimentos indígenas no Brasil, o que é expresso nas intensas mobilizações das Conferências Nacionais de Educação Escolar Indígena. Alguns autores chegam a considerar que os espaços de maior avanço na luta indígena por direitos têm sido no "campo da educação e da cultura, onde os desafios são grandes, porém mais permeáveis que os campos e contextos institucionais da política, da economia, do desenvolvimento e do direito" (GARCÉS et. al., 2019, p.17).

A geografia, assim como outras áreas do conhecimento, tem acompanhado estas transições entre os modelos de educação escolar indígena. Dentro desta modalidade de educação, esta área tem sido descrita no modelo intercultural-bilíngue como possuindo um papel fundamental no sentido de possibilitar, a estes povos, maneiras próprias de interpretar o espaço (BRASIL, 1998). Tal fato assume ainda mais relevância no contexto atual, marcado pela centralidade que a dimensão espacial-territorial possui na agenda política indígena.

Tendo em vista esta questão, objetiva-se no presente artigo compreender como a geografia tem sido incluída nos documentos normativos da educação escolar indígena. Prioriza-se, na análise aqui desenvolvida, o recorte histórico pós-1988, quando emerge o modelo intercultural-bilíngue. Ele está organizado em três seções, além da introdução e das considerações finais. Na primeira seção, discute-se a educação indígena e a educação escolar indígena como modalidades diferenciadas da educação. $\mathrm{Na}$ segunda seção, identificam-se os modelos de educação escolar indígena implementados ao longo da história nas comunidades indígenas. Na seção final do capítulo, o foco recai sobre a inclusão da geografia no atual modelo intercultural-bilíngue de educação escolar indígena, a partir dos documentos normativos.

\section{EDUCAÇÃO INDÍGENA E EDUCAÇÃO ESCOLAR INDÍGENA}

A educação indígena e a educação escolar indígena no Brasil não são um debate novo. Eles dizem respeito, pelo menos, a década de 1970 no Brasil, isso desconsiderando todo o debate educacional do período colonial que teve como base uma educação direcionada ao indígena para a consolidação do império colonial.

No entanto, este debate vem mudando ao longo dos anos, a partir da ressignificação do significado histórico-político dos povos originários para o Brasil e, em certa medida, as tensões provocadas pelo movimento indígena na defesa de um modelo educativo diferenciado e de caráter intercultural que influenciou as políticas públicas para o setor nas décadas de 2000 e 2010.

Neste sentido, nos propusemos a apresentar uma singela bibliometria para exemplificar como este debate veio se dando no Brasil a partir da dimensão quantitativa para, a seguir, mostrar suas transformações as partir do ponto de vista qualitativo. A metodologia utilizada é apresentada na Figura 01 e toma como referência 08 momentos para a construção de uma revisão bibliométrica a partir de uma análise quanti-qualitativa. A seleção dos dados toma como referência se eles apresentam conformidade ou não com o objetivo da pesquisa e o requerido em cada etapa. Havendo conformidade, o dado é encaminhado para a etapa seguinte. Não havendo, o dado é descartado.

Para a análise, fizemos três testes. O Primeiro foi utilizando a base Web Of Science e o segundo na base Scopus. Como nas duas bases o número de ocorrências foi pouco significativa para a nossa análise, optamos pela utilização da base Google Scholar, que apresenta uma quantidade e variedade de ocorrências muito maior. Optamos pelo uso do descritor "Educação Indígena" por considerar que ele é amplo o suficiente para representar o debate que estamos nos propondo analisar.

Como este trabalho é em caráter preliminar e por esta base não permitir o processamento automático dos dados, optamos por trabalhar com os 300 primeiros registros, dos quais, ao final do percurso 
metodológico, compuseram os gráficos 262 registros, tendo sido descartados 38 por: (a) não ter relação com o tema da pesquisa; (b) não ter sido apresentado em periódico ou livro científico; (c) constar com referências incompletas; (d) ter sido apresentado de maneira duplicada.

Figura 01 - Síntese da Metodologia Utilizada.

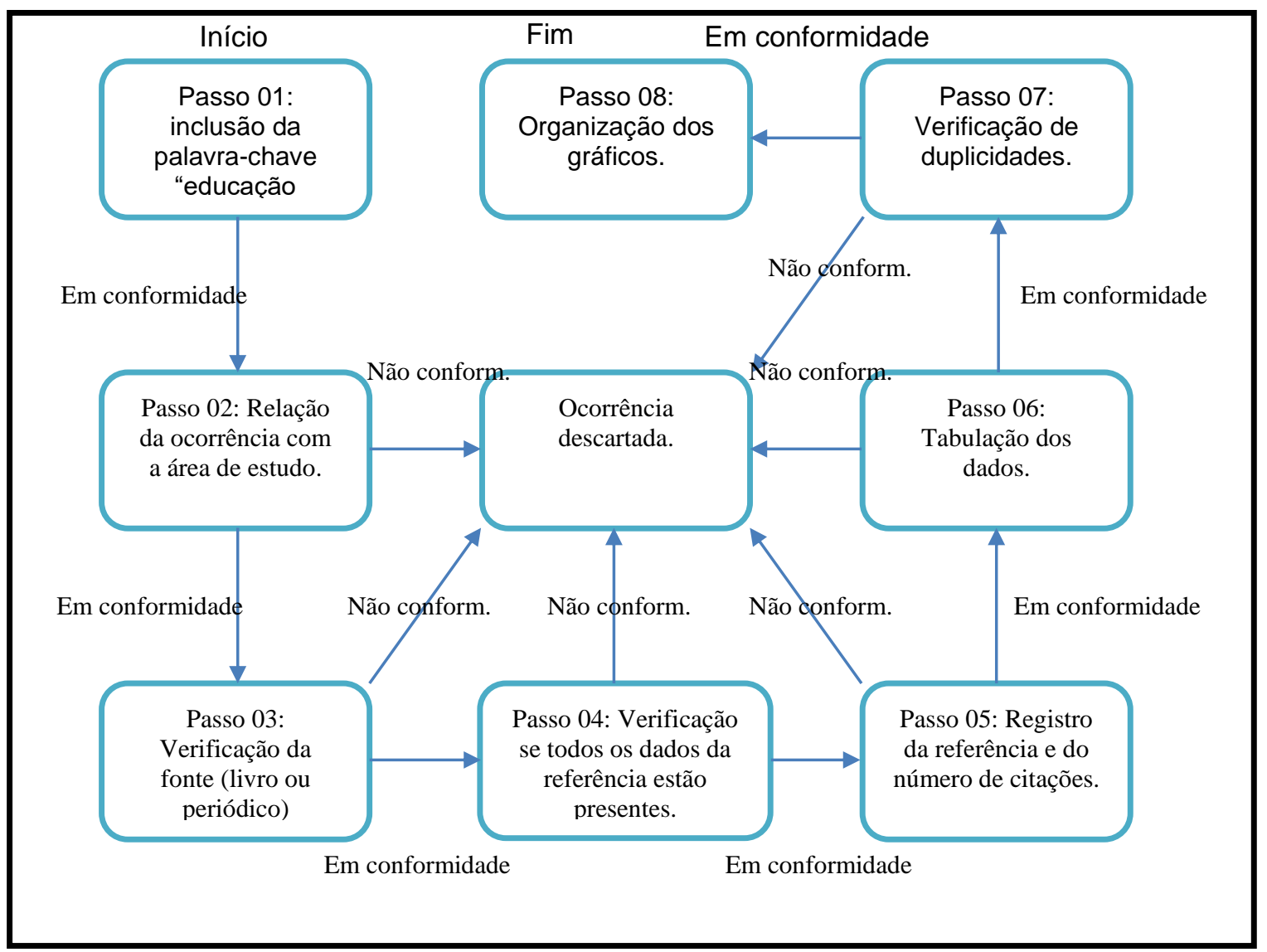

Fonte - Oliveira Neto, 2020.

Das 262 ocorrências, o trabalho mais antigo que contém a nossa base é Schaden (1976). A maior concentração de publicações encontra-se de 2001 a 2016, período em que se tem uma maior efervecência deste debate nas publicações analisadas, como apresenta a Figura 02.

Figura 02 - Distribuição dos trabalhos analisados (por ano).

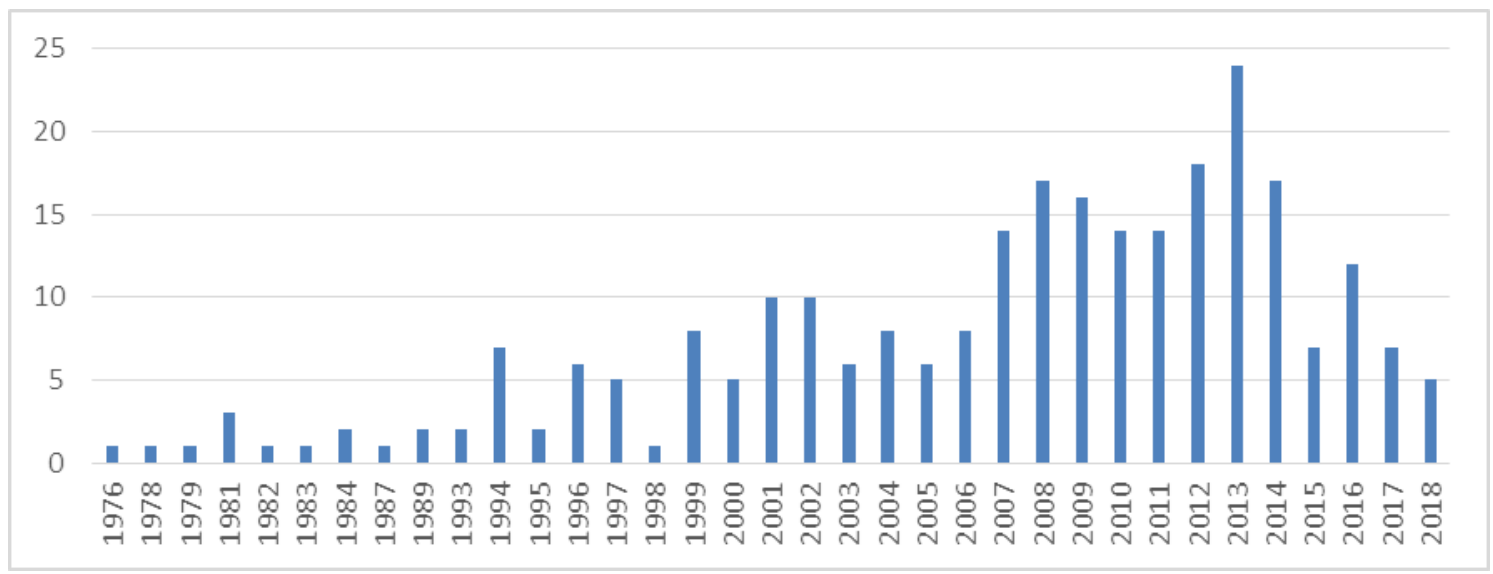

Fonte - Google Scholar. Organização: Oliveira Neto, 2020. 
Já a Figura 03 apresenta as 50 ocorrências da nossa base com maior impacto científico, medido a partir dos indicadores de citação do Google Scholar. Os círculos são proporcionais a quantidade de citação e as obras estão organizadas por ano de publicação

Figura 03 - Os 50 trabalhos com maior impacto, a partir do número de citações.

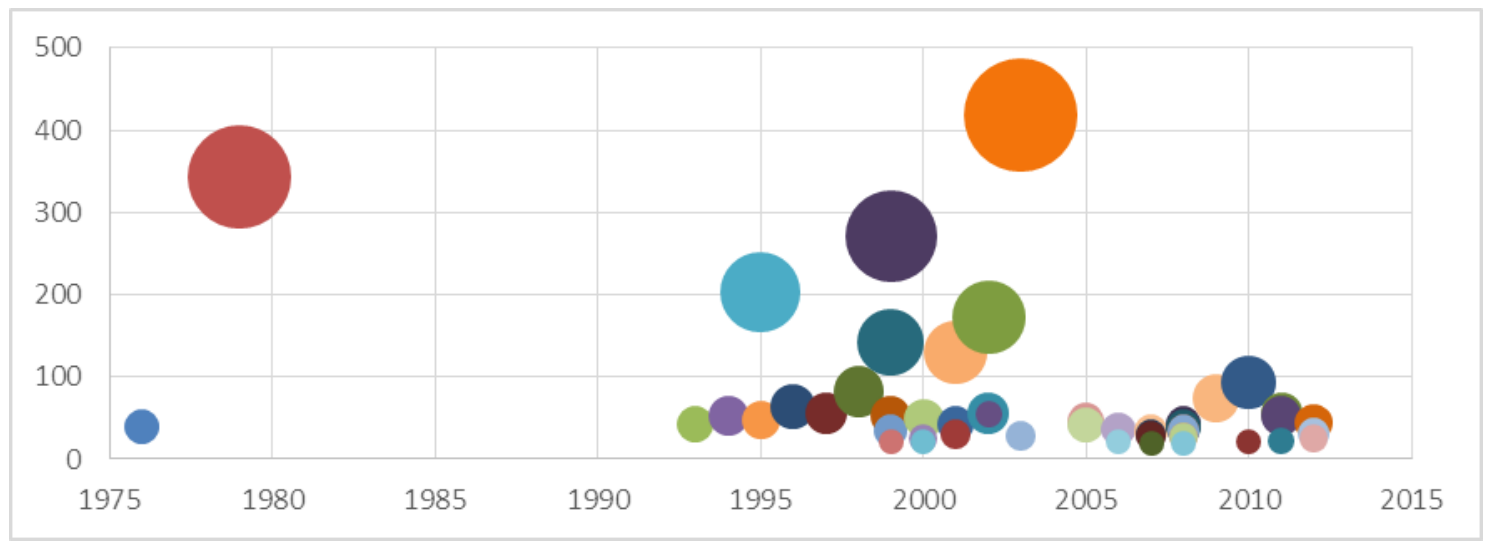

Fonte - Google Scholar. Organização: Oliveira Neto, 2020.

A partir dos dados apresentados na Figura 03, cabe destacar a influência no debate sobre educação escolar indígena dos trabalhos de Meliá $(1979,1999)$, Silva et. al. (1995, 2002), Cavalcanti (1999) e Fleuri (2003), a partir de perspectivas diferentes. No bojo destas perspectivas surgem discussões referentes a questões de extrema relevância para este campo de pesquisas, tais como alfabetização de crianças, contatos inter-étnicos, modelos de educação escolar e as aplicações da interculturalidade no campo educacional.

Embora as perspectivas destes autores divirjam, há a unanimidade em considerar que partir do processo histórico de subalternização dos povos e comunidades não-europeias, incluindo os povos nativos americanos, criou-se um estigma de que estes povos não possuíam educação, sendo, portanto, considerados bárbaros, incivilizados. Esta ideia justificava o processo de catequização destes povos, na medida em que os missionários convertiam os incivilizados em civilizados cristãos, sob os auspícios das ordens religiosas e das coroas metropolitanas.

Os sistemas de educação indígenas assumiam características diferenciadas com relação à educação escolarizada. Ao invés de se centrarem na figura da escola e dos elementos que a compõem (professores, currículos, livros, exames, etc.), a educação indígena tinha como principais aspectos "a observação, a experiência empírica e a autorreflexão proporcionadas por mitos, histórias, festas, cerimônias e rituais realizados para tal fim" (LUCIANO, 2006, p.130).

Dessa forma, não havia um único espaço nem um único momento para a criança ou o adolescente indígena aprender a cultura e a história de seu povo, já que isto ocorria ao caçar, pescar, criar artesanatos, participar de eventos comunitários e o próprio ato de brincar era levado em consideração como um momento educativo. Ponce (2015), citado por Silva (2019, p.47), salienta que o ponto central da educação indígena é de que "não existia nada superior aos interesses da coletividade e o ensino deve ser para a vida e por meio da vida".

Luciano (2006) identifica quatro eixos estruturantes para a educação indígena, a saber: o território, a língua, a economia e as relações de parentesco. Estes elementos compõem uma rede de conhecimentos que norteia as práticas de ensino-aprendizagem e, em última análise, o próprio sentido de existência de cada comunidade. O território, conceito com o qual os geógrafos têm desenvolvido muitas análises em contextos indígenas, é concebido por muitas destas comunidades para além da dimensão político-econômica-funcional, envolvendo também um poderoso conteúdo cultural-simbólico, passível de ser reproduzido e difundido por meio da educação. Assim:

o valor que, para ele, [o indígena] tem sua aldeia, a sua terra, as suas roças assume uma característica própria: este valor não é possível de ser medido por parâmetros econômicos, como geralmente acontece com o não-indígena. Para ele, seu território não é apenas "um punhado de terra" e sim uma herança de seus ancestrais, e como tal, é seu dever cultivar, proteger e repassar aos seus descendentes (SOUSA, 2018, p.43). 
Uma recente perspectiva de análise, oriunda da Arqueologia, desenvolve a hipótese de que o bioma amazônico contemporâneo tem um caráter antropogênico, isto é, as atividades humanas (dos povos originários), mediante "modos práticos diversos" sobre o espaço amazônico, tiveram um poderoso efeito de criação e dispersão de espécies vegetais, minerais e animais que, em última análise, consolidaram um dos ecossistemas mais ricos do planeta (MAGALHÃES, 2016).

Outra hipótese, a ser desenvolvida em futuras pesquisas, é que dentre estes "modos práticos diversos" estavam saberes espaciais, os quais foram historicamente difundidos entre os povos originários, por meio do que aqui denominamos de educação indígena. Assim, poder-se-ia argumentar que os saberes espaciais ocuparam, por milênios, papéis de destaque entre os povos da Amazônia.

Outra particularidade importante a ser ressaltada na educação indígena é a questão da transmissão de conhecimentos de uma geração a outra, num processo de ensino-aprendizagem cujo sentido partia dos mais velhos aos mais novos. Assim, os progenitores ensinavam aos seus descendentes os conhecimentos necessários para que estes, ao chegarem à idade adulta, mantivessem íntegra a cultura de seu povo, processo que se reiniciava a cada geração.

Além da família, a própria comunidade se encarregava de estabelecer relações de ensinoaprendizagem com os jovens indígenas. Nesse sentido, assumiam funções importantes as figuras dos sábios das aldeias, responsáveis por manterem conhecimentos específicos, como narrativas, músicas, rituais, práticas de xamanismo e cosmologias do povo.

Essa questão da transmissão de conhecimentos de geração em geração é fundamental para compreender como determinadas práticas indígenas sobreviveram por séculos, com alguns destes conhecimentos permanecendo nas memórias dos povos atualmente. É assim, para citar alguns exemplos, que os Tembé do Gurupi preservam em suas memórias as histórias sobre os encantados da prainha (SANTOS, 2017); os Assurini do Trocará contam a história da criação do mundo por Mahira (ASSURINI et. al., 2007); e os Baniwa continuam a realizar a festa do dabucuri com yurupari, ritual mais importante dos povos do Alto Rio Negro (LUCIANO, 2011). O relato abaixo, de uma acadêmica Suruí-Aikewara, ilustra bem essa característica:

Por exemplo, na realização de uma caçada, onde o filho acompanha seu pai, muitos ensinamentos são aprendidos. No momento da caminhada para o local de caça acontece o aprendizado sobre como se orientar na floresta através dos tipos de árvores, sobre a confecção da Tukasa que é um cercado de palha para prender a caça, sobre os animais que podem ou não fazer parte do consumo e sobre os ensinamentos da língua e das músicas Aikewara. (SURUÍ, 2016, p. 2).

As práticas de resistências das comunidades indígenas assumiam diversas dimensões, desde ações agressivas contra as escolas das missões religiosas até ações mais simbólicas, como a manutenção das línguas indígenas como principais meios de comunicação nas aldeias. Tamanha resistência provocou a constatação de que

\begin{abstract}
Apesar das políticas contrárias, o sentimento de pertencimento étnico expresso por estes povos não se esvaía tão facilmente e eles insistiam em manter suas identidades, que se materializam numa persistente distância face aos outros grupos Indígenas e face aos demais segmentos da sociedade brasileira. O tão esperado "índio genérico", que surgiria a partir do solapamento das diferenças culturais, sociais e ontológicas existentes entre eles não vingou, e pequenas populações reencontraram o eixo de seu crescimento demográfico e, reelaborando seus modos particulares de estar no mundo, firmaram-se enquanto coletividades diferenciadas (GRUPIONI, 2006, p.41).
\end{abstract}

A partir dos anos 1970 e 1980, contudo, as ações de resistência à instituição escolar, por parte dos povos indígenas no Brasil, assumem novas feições, apontando para uma crescente necessidade de uma "indigeneização da escola", isto é, da construção de escolas verdadeiramente indígenas, que possibilitem a estes povos manterem suas identidades e, em paralelo, construírem projetos políticos de autonomia perante a sociedade não-indigena. É neste contexto que os modelos de educação escolar indígena começam a ser rediscutidos.

\title{
OS MODELOS DE EDUCAÇÃO ESCOLAR INDÍGENA
}

Uma das demandas prioritárias por parte do movimento indígena atualmente é a educação escolarizada nas aldeias. Embora não exista um consenso entre os mais de 200 povos, nos termos

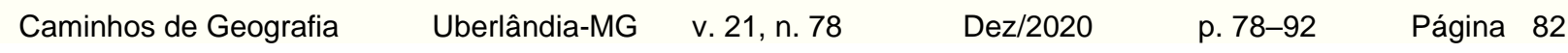


das Conferências Nacionais de Educação Escolar Indígena (CONEEl's), prevalece a ideia de que o modelo a ser efetivado nos currículos e nas práticas nas escolas indígenas deve ser o modelo Intercultural-Bilíngue.

Antes da emergência do modelo Intercultural, existiam outros modelos ao longo da história da educação escolar indígena que, conforme mencionado anteriormente, foi iniciada por meio da escola missionária nas aldeias. Assim, o primeiro modelo de educação escolar indígena é o catequético (BERGAMASCHI, 2005). Este modelo tinha como principal característica o trabalho de conversão ao cristianismo das comunidades nativas pelas ordens missionárias, predominantemente os Jesuítas, instalados no Brasil a partir de meados do século XVI.

No processo de escolarização dos povos ameríndios, os Jesuítas formularam metodologias que, de acordo com seus objetivos, eram mais eficazes. Assim que estabeleciam o domínio espacial-territorial sobre comunidades inteiras, mediante a política de aldeamento, os missionários procuravam obter o domínio intelectual sobre estes povos e, para tanto, não havia caminho mais adequado do que a escola, instituição portadora e difusora do racionalismo, do universalismo e dos ideais civilizatórios do mundo ocidental.

Dentro dos colégios missionários, o trabalho pedagógico consistia em tarefas para a criança e o jovem Indígena aprenderem conteúdos básicos da cultura não-indígena, tais como a religião cristã, o calendário e a língua portuguesa, combinando-os com a aprendizagem de cantos, rituais, orações e passagens da Bíblia. A geografia era secundária neste modelo e consistia em relatos de cronistas que acompanhavam expedições pelo continente (SOUZA; PEZZATO, 2010). Além disso, exigia-se que os estudantes aprendessem a realizar serviços básicos para torná-los mãos de obra das ordens religiosas. Em termos mais diretos, os missionários proibiam as crianças indígenas de serem indígenas, tornando-as escravas.

$\mathrm{Na}$ educação missionária, a catequização da criança indígena, desde os primeiros anos de sua vida, assumia um papel estratégico para o projeto de assimilação dos povos indígenas desenvolvido pelas ordens. Não era incomum, tampouco por motivo do acaso, que as crianças fossem retiradas de suas famílias para serem criadas em internatos; locais onde eram proibidas de se expressarem nas suas línguas maternas e viviam sem qualquer tipo de contato com seus parentes, conforme o relato pessoal de Luciano (2011, p.18), para quem "os maus-tratos sofridos no internato, os castigos físicos, a repressão moral e as violências de todos os tipos foram fortes e inesquecíveis".

Nas escolas indígenas missionárias, além de aprenderem os conteúdos escolares, os estudantes também aprendiam a catequizar os seus próprios parentes e, por este motivo, quando atingiam determinada idade, eram enviados às aldeias (GRUPIONI, 2006). Em muitos casos, estes indígenas não cumpriam suas missões na medida em que:

\begin{abstract}
não tinham mais laços afetivos com seus parentes, pois haviam vivido longe deles a maior parte de suas vidas; não conseguiam se comunicar na língua de origem porque ela fora soterrada na escola monolíngue; não se integravam a vida cotidiana e ritual do grupo, pois Ihes faltavam referenciais para entender e viver aquele modo de vida. Seu caminho natural era a busca por centros urbanos, integrando-se aos estratos mais baixos da vida produtiva e social. (GRUPIONI, 2006, p.44)
\end{abstract}

Esta sensação de estranhamento provocada no estudante indígena era consequência das contradições existentes entre os modelos de educação indígena e educação escolar. Enquanto a primeira expressava uma concepção de mundo vinculada às cosmologias dos povos indígenas, a segunda era vinculada a uma concepção de mundo radicalmente diferente e que, por almejar a universalização, negava a este estudante a importância da primeira, colocando-o em uma espécie de encruzilhada entre o seu povo de origem e o povo que o havia ensinado a ser civilizado, conforme a perspectiva colonizadora.

Este modelo educacional perdurou durante os séculos posteriores e permanece ainda hoje em algumas escolas indígenas, embora não seja o predominante atualmente. Contudo, devido a este longo período de aplicação, os efeitos da educação missionária são perceptíveis nas memórias e nas trajetórias de muitas comunidades indígenas pelo Brasil. Um dos mais dramáticos aspectos reside na questão linguística: calcula-se que desde os anos iniciais de colonização, $75 \%$ das línguas indígenas foram extintas (RODRIGUES, 1993). Em parte, isto se deve à metodologia de exclusão das línguas indígenas aplicada por este modelo educacional.

A partir do processo histórico da expulsão dos Jesuítas nas reformas Pombalinas, o modelo de educação missionária passou por uma série de crises, na medida em que a coroa Portuguesa e,

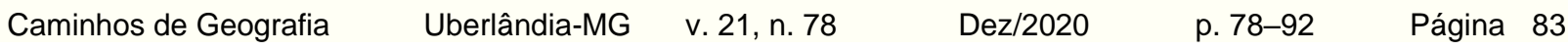


posteriormente, o Império Brasileiro assumiram para si o controle da política indigenista, inclusive no que se refere a educação escolar Indígena. Tassinari (2008) identifica uma transição entre o modelo missionário e outro modelo de escola indígena entre o final do século XIX e o início do XX, com o surgimento do órgão Indigenista oficial, sugestivamente batizado de Serviço de Proteção aos Índios e Localização de Trabalhadores Nacionais (SPILTN), em 1910.

O SPTILTN, posteriormente renomeado de Serviço de Proteção ao Índio (SPI), possuía uma perspectiva ambígua com relação aos povos indígenas em comparação as antigas ordens missionárias, caracterizada como uma política indigenista de tutela sobre os "índios incapazes". O extinto SPI, que teve como figura central Marechal Rondon, assumia para si a missão de pacificar (conforme o jargão oficial) os povos indígenas, integrando-os à sociedade nacional e transformandoos em povos sedentários, para não serem exterminados pelas frentes de expansão capitalistas, que naquele momento se dirigiam ao interior do território brasileiro ${ }^{1}$.

Devido à influência positivista, recorrente na sociedade do início do século $\mathrm{XX}$, a perspectiva do SPI sobre a questão indígena identificava os povos em algumas fases lineares. Na fase inicial, estavam aqueles povos não tutelados pelo Estado, sendo, por isso, considerados bravos, selvagens. Dessa forma, o referido serviço enviava frentes de pacificação, isto é, equipes que realizavam contatos com estes indígenas, atraindo-os para postos de atração do SPI.

A partir desta fase inicial de contato, conforme assinala Tassinari (2008), a educação escolar adquiria um importante sentido nos projetos do SPI, "funcionando como uma estratégia para a 'civilização' dos Índios no Interior de uma política de integração da nação" (TASSINARI, 2008, p.222). No modelo SPI, fundamentado no positivismo, os currículos das escolas eram baseados em conteúdos de língua portuguesa e matemática, bem como técnicas básicas de agricultura, pecuária, comércio e indústria; estas últimas consideradas importantes para inserir os povos em frentes de trabalho, espécie de fase final, na qual tais povos seriam, definitivamente, assimilados sociedade não-indígena.

Desde seu surgimento, o modelo SPI de educação escolar indígena sofreu com numerosas críticas e resistências dos povos, de modo que, em alguns casos, o órgão evitou o termo escola, "para fugir das conotações negativas que esta designação tem para os índios, como de um lugar onde se confina as crianças durante longas horas de cada dia, submetendo-os a uma disciplina forçada e em prejuízo de outras atividades que Ihes parecem mais úteis" (CUNHA, 1990, p.89-90, citado por OLIVEIRA; NASCIMENTO, 2012). Este quadro, somado ao processo de formação de novas gerações de antropólogos e indigenistas, a partir da formação das primeiras Universidades, além da consolidação da atuação do Museu Nacional e do Museu Goeldi, colaborou para que o fenômeno da escolarização em contextos indígenas começasse a ser estudado com maior profundidade.

Tassinari defende que a década de 1960 marca uma transição entre o já decadente Modelo SPI e o modelo implementado pela recém-criada Fundação Nacional do Índio (FUNAI), em 1967. Esta transição, marcada por "rupturas e continuidades", é influenciada pelas novas concepções de antropólogos e linguistas, profissionais que reconheceram e privilegiaram a utilização das línguas Indígenas como meios para a alfabetização dos jovens estudantes. Contraditoriamente, este reconhecimento levou ao estabelecimento do bilinguismo de transição, o qual

\begin{abstract}
Foi adotado como estratégico para o efetivo aprendizado do português e dos valores da sociedade dominante: valorizava-se a língua indígena porque ela era a chave para o aprendizado da língua nacional. Esse método, usado pelo Estado em conjunto com as missões religiosas [...] só serve para que as crianças saiam do monolinguismo de sua língua de origem para o monolinguismo em português. (GRUPIONI, 2006, p.44).
\end{abstract}

Conforme explicitado pelo autor, no modelo da FUNAI houve uma reaproximação do órgão indigenista com as missões religiosas (católicas e protestantes), que desempenharam funções essenciais nesta modalidade de educação, frequentemente representando a própria Fundação nas aldeias e recebendo capital governamental para suas operações. Merece destaque a atuação do Summer Institute of Linguistics (SIL), de origem protestante, que chegou a atuar "junto a 53 povos Indígenas no Brasil com o ensino bilíngue, voltado à conversão religiosa" (LUCIANO, 2011, p.94-95).

\footnotetext{
1 De acordo com Ribeiro (2017) a política indigenista brasileira do século XX, influenciada fortemente por Rondon, era alicerçada em quatro princípios, a saber: 1) morrer, se preciso for, matar, nunca, ou seja, estabelecer contatos através de termos pacíficos com estes povos; 2) respeito as nações indígenas; 3) garantir aos indígenas seus territórios; 4) assegurar aos índios a proteção direta do Estado, não como um ato de caridade ou de favor, mas como um direito.
}

\begin{tabular}{|c|c|}
\hline & Uberlândia-MG \\
\hline
\end{tabular}


Um quadro realista, no que se refere a este modelo educacional, é encontrado em Santos (1975), um dos primeiros a realizar pesquisas sistemáticas e abrangentes sobre as escolas em aldeias. A partir de suas experiências em dezenas de contextos escolares, o referido autor constata as contradições e os limites da educação escolarizada do modelo FUNAI/SIL. O referido autor salienta, por exemplo, que tal modelo teve consequências negativas para as comunidades, na medida em que "não cumpre minimamente a função educativa" (SANTOS, 1975, p.09), o que contribuiu para novas formas de preconceito contra os indígenas brasileiros.

Apesar das consequências negativas, Tassinari (2008) identifica neste modelo as sementes do que a viria ser um novo capítulo na história da educação escolar indígena. Isto porque, a partir deste momento, de acordo com a autora, houveram as primeiras iniciativas para a formação de professores indígenas, então denominados de "monitores bilíngues", alguns dos quais lideraram os movimentos indígenas na década de 1980 e 1990. Vale ressaltar que estas décadas também marcam um ponto de virada, no que se refere às mobilizações para a afirmação de direitos indígenas, expressa na aproximação entre estas populações, setores das Universidades e movimentos sociais diversos (CUNHA; ALMEIDA, 2009).

Naquele momento histórico, propício a transições, o modelo de educação escolar indígena a ser implementado nas aldeias também passou por uma série de questionamentos, o que acarretou a idealização de um novo modelo, radicalmente distinto dos modelos anteriores. Com efeito, houve o desenvolvimento de um novo projeto educacional para as escolas indígenas, desta vez alicerçada nos princípios da interculturalidade, do bi-multilínguismo e da educação diferenciada e específica (TASSINARI, 2008).

Este novo modelo, alcunhado de Intercultural-Bilíngue, tem se consolidado nas recentes décadas dentro da agenda dos movimentos indígenas no Brasil, os quais têm obtido gradativamente funções de protagonistas na elaboração das políticas educacionais voltadas aos seus contextos. Esta nova atitude Indígena contrasta, portanto, com as resistências aos modelos anteriores. Nas palavras de Luciano (2011, p.76) "não se trata mais de discutir se é desejável ou não a escola nas aldeias, mas que modelos de escola e de educação, qual lugar ocupa no imaginário etnopolítico e quais impactos e resultados podem gerar nas comunidades".

A educação escolar indígena, no seu atual modelo, foi instituída oficialmente por meio do Parecer $n^{\circ}$ 14 e da Resolução oㅜ 03, do Conselho Nacional de Educação (CNE), utilizando dispositivos já previstos na Constituição Federal de 1988 e na Lei de Diretrizes e Bases da Educação, de 1996, bem como na Convenção 169 da Organização Internacional do Trabalho (OIT), de 1989. Na resolução do CNE consta, dentre outras coisas, que as escolas indígenas devem promover o ensino intercultural e bilíngue "visando à valorização plena das culturas dos povos indígenas e afirmação e manutenção de sua diversidade étnica" (BRASIL, 1998, p.18).

Nestes documentos foi determinado que o Ministério da Educação (MEC) seria o órgão responsável pela coordenação das ações de educação escolar indígena no país, por meio da definição de diretrizes curriculares para a oferta de educação escolar aos povos indígenas; assistência técnicofinanceira aos sistemas estaduais de ensino, para oferta de programas de formação de professores indígenas; de publicação de materiais didáticos diferenciados e elaboração de programas específicos para atendimento das necessidades das escolas indígenas, visando à melhoria nas condições de ensino; e gestão educacional nas aldeias. Tais prerrogativas têm culminado, desde os anos de 1990, em uma série de documentos normativos para esta modalidade de educação.

Em paralelo aos fatos supracitados, a geografia assumiu um importante papel neste modelo de educação escolar indígena, em decorrência da proximidade do objeto de estudo desta ciência, o espaço-geográfico, com as demandas dos movimentos indígenas contemporâneos, em especial a luta por demarcação dos territórios indígenas, que deram origem à categoria jurídica das Terras Indígenas.

Tal aproximação resultou nas primeiras experiências de geógrafos neste campo de pesquisa. A Tese de doutorado de Resende (1992), a respeito do currículo desta disciplina em projetos de Formação de Professores Indígenas da Comissão Pró-Índio do Acre, é identificada em um levantamento realizado por Grupioni (2008) como sendo pioneira na relação geografia-educação escolar indígena. A partir desta época, também são observados os primeiros materiais didáticos específicos de geografia nas escolas indígenas, em especial mapas e atlas.

$\begin{array}{llllll}\text { Caminhos de Geografia } & \text { Uberlândia-MG } & \text { v. 21, n. } 78 & \text { Dez/2020 } & \text { p. } 78-92 & \text { Página } 85\end{array}$


De que forma este aumento da importância da geografia na educação escolar indígena pode ser observado em uma análise dos documentos normativos desta modalidade de educação atualmente? Este é o questionamento que anima a próxima seção deste artigo.

\section{A GEOGRAFIA NA ATUAL POLÍTICA NACIONAL DE EDUCAÇÃO ESCOLAR INDÍGENA}

Conforme discutido na seção anterior, as políticas escolares para os povos indígenas foram iniciadas durante o período colonial e, desde então, têm sido norteadas por modelos, do modelo catequéticomissionário ao modelo intercultural-bilíngue. Este último é o predominante atualmente e conta com uma série de documentos que normatizam suas atividades. Com o objetivo de tornar didática a apresentação dos principais documentos normativos da atual política nacional de educação escolar indígena, elaboramos a seguinte linha cronológica:

Figura 04 - Linha do tempo da Educação Escolar Indígena Pós-1988.

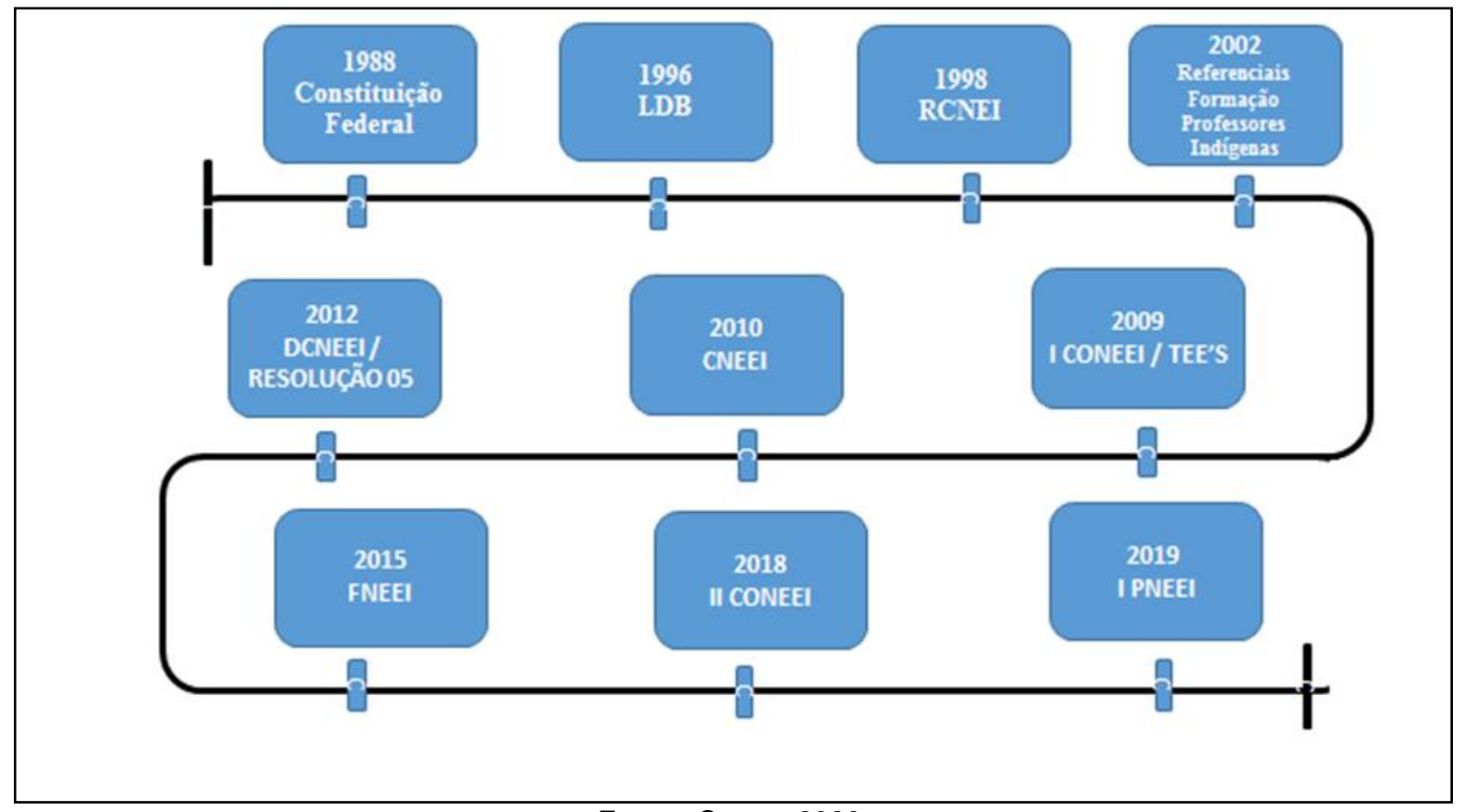

Fonte - Sousa, 2020.

Em consonância com a proposta da presente seção, nas próximas páginas, o foco será analisar como a geografia tem sido incluída nestes documentos. Observa-se que enquanto a Constituição Federal e a LDB reconhecem legalmente as diferenças e particularidades desta modalidade de educação, bem como os princípios da interculturalidade, do bi-multilinguismo e da educação diferenciada e específica, não há uma menção explicita à geografia, embora mencionem que as escolas devem "garantir aos índios, suas comunidades e povos, o acesso às informações, conhecimentos técnicos e científicos da sociedade nacional e demais sociedades indígenas e não-indias" (LDB, Art.78, II), estando, portanto, implícito que a geografia é um destes conhecimentos.

Diferentes daqueles dois documentos, o Referencial Curricular Nacional para as Escolas Indígenas (RCNEI), lançado em 1998, aprofundou a importância da geografia nesta modalidade de educação, inserindo-a como um componente curricular básico nos projetos políticos pedagógicos e nas práticas dos docentes vinculados às escolas indígenas. Há, inclusive, uma seção exclusivamente destinada à geografia, que está dividida da seguinte forma: I. Por que estudar geografia nas escolas indígenas; II. Para que estudar geografia?; III. Sugestões de Temas; IV. Sugestões de trabalho; V. O ensino da geografia e a avaliação; VI. Indicações para a formação do professor; VII Bibliografia.

O RCNEI aborda a concepção de geografia de alguns povos indígenas, constantemente inserindo os relatos de professores e pensadores indígenas, embora também dialogue com os conceitos próprios 
da ciência geográfica, citando nominalmente os conceitos de paisagem, lugar e território, fornecendo a seguinte descrição:

o que se vê - as paisagens;

o que se sente e com que a pessoa se identifica - os lugares

o que são referências significativas para os povos e os indivíduos, para conviver, trabalhar, e produzir sua cultura - os territórios. (BRASIL, 1998, p.227).

No RCNEl/Geografia é possível observar sugestões de temas relacionados a várias subáreas da ciência geográfica, desde a geografia física (muitas vezes dialogando com a Educação ambiental), passando pela geografia agrária e até mesmo pela geografia política. Mas, há uma área da geografia que é realçada em vários pontos do texto: a cartografia. Esta é, sob aquele ponto de vista, um eixo transversal da geografia na educação escolar indígena haja vista que "para cada parte do estudo da geografia, pode-se ir fazendo a cartografia, através dos mapas, que são o desenho, a representação daquela ideia como meio de comunicação e leitura" (BRASIL, 1998, p. 238).

Além deste conjunto de possibilidades temáticas, o RCNEI/Geografia também fornece sugestões aos educadores para o trabalho com tal ciência, alertando, inclusive sobre a indissociabilidade dos aspectos humanos e naturais na produção do espaço-geográfico e de como a pesquisa em geografia pode se tornar uma poderosa ferramenta no processo de ensino-aprendizagem nas escolas indígenas. Outra poderosa ferramenta para o ensino de geografia, de acordo com o documento, é a produção conjunta (entre alunos e professores) de materiais didáticos específicos para as escolas indígenas, dentre os quais mapas, atlas, maquetes e roteiros de excursão pelo território.

A necessidade de professores oriundos das próprias comunidades para o trabalho nas escolas indígenas, conforme previsto na legislação, deu origem aos Referenciais para a Formação de Professores Indígenas, em 2002. O referido documento teve como objetivo contribuir para a criação e implementação de programas de formação inicial (cursos de Magistério e Licenciaturas Interculturais Indígenas), assim como de formação continuada de professores indígenas.

Neste documento a geografia surge como uma ferramenta em potencial para que os professores indígenas possam refletir "criticamente sobre as relações Interétnicas mantidas com a sociedade nacional" (BRASIL, 2002, p.26). A partir da citação extraída, infere-se que a concepção de geografia apresentada no referido documento citado está em consonância com os princípios do ensino de geografia do século XXI, o qual postula que o professor de geografia deve:

ensinar - ou melhor, deixar o aluno descobrir e refletir sobre - o mundo em que vivemos, com especial atenção para a globalização e para a escala local, isto é, do lugar de vivência dos alunos [...]. Deve enfocar criticamente a questão ambiental e as relações sociedade/natureza, sem embaralhar a dinâmica de uma delas na outra. Deve realizar, constantemente, estudos do meio para que o conteúdo ensinado não seja meramente teórico ou "livresco" e, sim, real, ligado à vida cotidiana das pessoas. Deve contribuir, junto com outras disciplinas, para a sociabilidade entre os educandos, para a ausência de preconceitos, para a aprendizagem do diálogo e da troca de experiências. Deve, enfim, levar os educandos a interpretar textos, fotos, mapas, paisagens (por meio de ilustrações ou in loco), enfocando os problemas sócioespaciais, a inter-relação entre os fenômenos, as causas que viram efeito e vice-versa. (VESSENTINI, 2009, p.92).

Aspecto essencial no que diz respeito à geografia, neste referencial, consiste no papel que os cursos de formação têm em qualificar professores-pesquisadores em geografia dentre as próprias comunidades, que sejam capazes de compreender e analisar as maneiras como suas escalas geográficas locais têm sido inseridas em escalas geográficas mais abrangentes. Isso, tendo em vista que a globalização e seus efeitos chegam com cada vez mais intensidade aos espaços cotidianos dos indígenas; o maior exemplo disso são as pressões políticas, econômicas e sociais sobre os territórios ocupados por estes povos, além de dinâmicas culturais até então inéditas a estas comunidades, como as redes sociais e a articulação dos movimentos sociais indígenas.

Este referencial serviu de amparo ao Programa de Apoio à Formação Superior e Licenciaturas Interculturais Indígenas (PROLIND), em 2005, a partir do qual foram submetidos e aprovados numerosos projetos político-pedagógicos dos cursos de Licenciatura Indígena. Dado o objetivo do presente artigo, acreditamos que é importante tecer breves comentários a respeito de como a geografia é abordada nos PPP's destes cursos.

Observa-se, de início, que a geografia está frequentemente categorizada como uma das ciências humanas nas grades curriculares destes cursos, junto a história, a sociologia e a filosofia. $\mathrm{Na}$

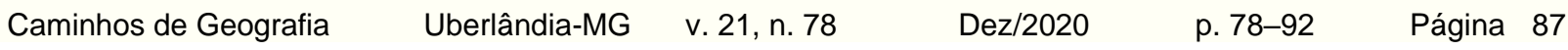


realidade, o egresso é habilitado ao exercício do magistério na educação básica, com atuação em uma das três grandes áreas da ciência, normalmente ciências humanas e sociais, ciências exatas e da natureza, além de linguagens e artes. Assim, o professor de geografia diplomado por tais cursos é, de fato, habilitado para docência em ciências humanas. Apesar disso, nas grades curriculares, há disciplinas específicas da geografia.

As disciplinas oriundas da geografia nestes cursos apontam para uma preferência dada aos conceitos de território e territorialidade, o que é identificável pela recorrência com a qual determinadas disciplinas são batizadas com estes mesmos nomes. Tal fato vai de encontro ao previsto na Resolução no 01 CNE/MEC, de 07 de Janeiro de 2015, a qual prevê que a centralidade destes conceitos na formação de professores indígenas é "estratégica para a continuidade dos povos e das comunidades indígenas em seus territórios, contribuindo para a viabilização dos seus projetos de bem-viver" (BRASIL, 2015, Art. 8, p.04).

Em paralelo a essa centralidade do conceito de território, a geografia ofertada nestes cursos também engloba outros conceitos da epistemologia geográfica. É neste sentido que o curso da Universidade Federal do Amapá (UNIFAP) oferta disciplinas ligadas à cartografia (sob o nome etnocartografia), a geografia regional e a geografia do Brasil; enquanto na Universidade Federal do Amazonas (UFAM) existem disciplinas como organização do espaço-geográfico e alfabetização cartográfica. Em alguns destes cursos a dimensão socioambiental, cada vez mais relevante nos contextos indígenas, também recai sobre a geografia, como no caso da disciplina território, etnodesenvolvimento e sustentabilidade dos povos indígenas, ofertada no curso da Universidade do Estado do Pará (UEPA).

A realização da I Conferência Nacional de Educação Escolar Indígena (I CONEEI), em 2009, representou um importante momento para a educação escolar indígena no Brasil. Este evento, na realidade, resultou de uma série de conferências locais e regionais, as quais abriram espaço para que as entidades indígenas e indigenistas, que contabilizaram o expressivo quantitativo de 45.000 pessoas, elencassem experiências, desafios, potencialidades e novas demandas para esta modalidade de educação, sintetizadas em um documento final, homônimo à conferência (BRASIL, 2014).

No documento citado, apesar da não menção direta à geografia, os conceitos de território, territorialidade e região foram concebidos como centrais na elaboração das políticas educacionais referentes aos povos indígenas, de tal modo que foram discutidas as implementações dos territórios etnoeducacionais (TEE's), conforme sinaliza o decreto 6.861, de 27 de maio de 2009.

Em termos gerais, os TEE's são regiões geográficas que agrupam uma determinada quantidade de povos indígenas, respeitando os aspectos socioculturais, demográficos, linguísticos, históricos e territoriais destes. Possuem o objetivo de incluir tais espaços interinstitucionais no ciclo de políticas públicas da educação escolar indígena, por meio de conselhos gestores nos quais as lideranças indígenas e setores da sociedade civil são convidados a participar ativamente. Assim, os TEE's expressam as territorialidades particulares dos povos indígenas, as quais não necessariamente são iguais aos limites político-administrativos tanto dos municípios quanto das unidades da federação.

A década de 2010, por seu turno, apresentou importantes avanços na política de educação escolar indígena, consolidando o modelo intercultural-bilíngue. Em 2010 foi criada a Comissão Nacional de Educação Escolar Indígena (CNEEI), composta por representantes Indígenas, governamentais e da sociedade civil. Em 2012 foram publicadas as Diretrizes Curriculares Nacionais para a Educação Escolar Indígena na Educação básica (Resolução CNE/CEB n.05), as quais reafirmam que um dos princípios desta modalidade de educação deve ser a "centralidade do território para o bem viver dos povos indígenas e para seus processos formativos e, portanto, a localização das escolas em terras habitadas por comunidades indígenas, ainda que se estendam por territórios de diversos Estados ou Municípios contíguos". (BRASIL, 2012, p. 03, Art. 4º I)

O referido documento também orienta que as escolas indígenas devem priorizar "o uso de materiais didático-pedagógicos produzidos de acordo com o contexto sociocultural de cada povo indígena" (Idem, Art. 5ำ, IV). Essa normativa abriu caminho para a elaboração e utilização de materiais didáticos de geografia nas escolas indígenas, em especial livros didáticos, mapas, atlas, maquetes e até mesmo globos terrestres. Em algumas ocasiões, estes materiais foram elaborados como atividades de discentes dos já citados cursos de licenciaturas interculturais indígenas, que nos seus processos formativos estimulam a produção geográfica e cartográfica indígena. 
Mais recentemente, no rescaldo das novas dinâmicas que perpassam os contextos educacionais e indígenas, o ministério da educação e os movimentos indígenas articularam a realização da II CONEEI, em 2018, evento no qual buscou-se aperfeiçoar as bases das políticas e a gestão de programas e ações para o tratamento qualificado desta modalidade de educação (BRASIL, 2018), reafirmando os princípios da interculturalidade, do bi-multilinguismo e da especificidade.

Estruturada em torno de cinco eixos temáticos, a II CONEEI reafirmou a centralidade da questão territorial nesta modalidade de educação e, em paralelo, lançou novas bases para a inclusão da geografia nos contextos escolares indígenas, especificamente no que se refere à necessidade de valorização de práticas pedagógicas diferenciadas a serem desenvolvidas pelos docentes. A geografia deve surgir nestas práticas diferenciadas como um instrumento para o fortalecimento das relações comunitárias, das identidades étnicas e, principalmente, nos processos de sustentabilidade socioambiental (BRASIL, 2018), em virtude das dinâmicas que tornam estes povos em importantes agentes nas políticas ambientais em nível global, particularmente na Amazônia. Além disso, quando o documento final da conferência demanda que:

O MEC e demais órgãos responsáveis pela educação garantam o acesso as novas tecnologias, com cursos de inclusão digital e de tecnologias educativas, além de estrutura física adequada para todas as escolas, núcleos e extensões Indígenas, por meio da instalação e manutenção de laboratórios científicos e de informática com acesso a internet de boa qualidade nas escolas Indígenas, bem como equipamentos com memória suficiente para apoiar a documentação digital e a prática pedagógica diferenciada (BRASIL, 2018, p.48)

$\mathrm{Na}$ perspectiva aqui empregada, o trecho acima indica uma abertura para que, dentro desta modalidade de educação, as escolas indígenas, de acordo com suas especificidades, comecem a desenvolver atividades associadas a técnicas mais recentes da geografia, como GPS, softwares de geoprocessamento e cartografia digital, instrumentalizando-as para que sejam inseridas como ferramentas úteis aos povos indígenas. Recentes experiências e pesquisas vêm demonstrando que é plenamente possível a inserção gradual destas novas tecnologias aos contextos educacionais indígenas, estabelecendo interfaces entre os conhecimentos geográficos dos povos indígenas e os conhecimentos geográficos dos não-Indígenas (CARVALHO, 2006; GAVAZZI, 2012). Neste aspecto reside, possivelmente, o futuro da geografia na educação escolar indígena.

\section{CONSIDERAÇÕES FINAIS}

O desenvolvimento do presente artigo possibilitou atingir o objetivo proposto, ou seja, compreender como a geografia tem sido incluída no modelo intercultural-bilíngue de educação escolar indígena. Para alcançar tal intento, lançamos mão de levantamento bibliográfico e documental, além de revisão bibliométrica, analisando como esta ciência e seus conceitos têm sido abordados nos documentos normativos desta modalidade de educação.

Tomamos como ponto de partida para nossa análise os modelos anteriores de educação escolar indígena, os quais ocasionaram uma ruptura com a educação indígena, iniciando pelo modelo catequético-missionário, passando pelo modelo SPI e, posteriormente, pelo modelo da FUNAI.

Apesar das diferenças entre esses três modelos, consideramos que existem pelo menos duas semelhanças: I) Os modelos eram voltados para a assimilação dos povos indígenas e a cultura da sociedade não-Indígena; II) A geografia escolar era secundária nos currículos e nas práticas pedagógicas das escolas indígenas, em comparação a outras áreas do conhecimento.

Observamos que após a transição para o modelo intercultural-bilíngue, a partir das décadas de 1980 e 1990, a geografia obteve relevância nos principais documentos normativos que orientam esta modalidade de educação. Como resultado, a geografia escolar se tornou componente curricular básico nos projetos políticos pedagógicos e nas práticas dos docentes vinculados as escolas indígenas.

Conforme a análise efetuada, a geografia da atual política educacional indígena tem sido centrada nos conceitos de território e territorialidade, considerando-os como estratégicos para as práticas educativas nas escolas indígenas, na medida em que podem colaborar tanto para os projetos comunitários quanto para os projetos de autonomia destes povos frente à sociedade não-Indígena. 
Em paralelo a isso, a geografia também tem sido indicada como importante para estes povos compreenderem as dinâmicas espaciais contemporâneas, particularmente aquelas mais diretamente relacionadas aos seus contextos, das quais se destaca a questão socioambiental. Neste sentido, é importante ressaltar que, para os documentos normativos, tal compreensão espacial poderá ser alcançada por meio da cartografia, concebida no RCNEI como um eixo transversal na geografia nesta modalidade de educação.

\section{AGRADECIMENTOS}

Agradecimento a Fundação Amazônia Paraense de Amparo e Estudos e Pesquisas (FAPESPA) pela concessão de bolsa de pesquisa.

\section{REFERÊNCIAS}

ASSURINI, M; RODRIGUES, A.D; CABRAL, A.S.A.C. Livros de relatos Assurini 2. UFMG, Belo Horizonte/MG, 2005.

BERGAMASCHI, M.A. Nhembo'e: enquanto o encanto permanece - Processos e práticas de escolarização nas aldeias Guarani. Tese (Doutorado em Educação). UFRGS, Porto Alegre/RS, 2005.

BRASIL. II Conferência Nacional de Educação Escolar Indígena (CONEEI): Fortalecendo o protagonismo Indígena na Educação. Brasília: MEC, 2018

BRASIL. Constituição Federal de 1988. Brasília: Ministério da Justiça, 1988.

BRASIL. Diretrizes Curriculares Nacionais para a Educação Escolar Indígena na Educação Básica: Resolução CNE/CEB n05. Brasília: CNE/MEC, 2012.

BRASIL. I Conferência Nacional de Educação Escolar Indígena: Documento Final. Brasília: SECADI, 2014.

BRASIL. I Plano Nacional de Educação Escolar Indígena (PNEEI): Versão para debate. Brasília: MEC, 2019.

BRASIL. Lei n. 9394 / Lei de Diretrizes e Base da Educação (LDB). Brasília: Ministério da Justiça, 1996.

BRASIL. Referenciais para a Formação de Professores Indígenas. Brasília: MEC/SEF, 2002.

BRASIL. Referencial Curricular Nacional para as Escolas Indígenas. Brasília: MEC/SEF, 1998.

BRASIL. Resolução CNE/SEB no 1, de 07 de janeiro de 2015. Ministério da Educação, Brasília: MEC/CNE/SEB, 2015.

CARVALHO, A.L.A. O geoprocessamento na gestão ambiental em terras indígenas: uma experiência com etnomapeamento junto à comissão pró-índio do Acre. Dissertação (Mestrado em Geografia Física) - FFLCH/USP. São Paulo/SP, 2006.

CAVALCANTI, M. C. Estudos sobre educação bilíngüe e escolarização em contextos de minorias lingüísticas no Brasil. DELTA: Documentação de Estudos em Lingüística Teórica e Aplicada, v. 15, n. SPE, p. 385-417, 1999. https://doi.org/10.1590/S0102-44501999000300015

CUNHA, L. O. P. A política indigenista no Brasil: as escolas mantidas pela FUNAl. Dissertação (Mestrado em Educação) - Faculdade de Educação. Universidade de Brasília, Brasília, DF, 1990.

DA CUNHA, M.C.; ALMEIDA, M. W. B. Populações tradicionais e conservação ambiental. In: CUNHA, Manuela Carneiro da (Org.). Cultura com aspas. São Paulo: Cosac Naify, 2009. p. 277-300.

DA SILVA, A.L.; FERREIRA, M. K. L. Antropologia, história e educação: a questão indígena e a escola. 2001.

DA SILVA, A.L; GRUPIONI, L.D.B; MACEDO, A.V.L. A temática indígena na escola: novos subsídios para professores de $1^{\underline{a}}$ e $2^{\underline{a}}$ graus. MEC, 1995.

DA SILVA, A.L; NUNES, A; DA SILVA M.A.V.L. Crianças indígenas: ensaios antropológicos. FAPESP, 2002 
FLEURI, R.M. Interculturalidade e educação. Revista brasileira de educação, n. 23, p. 16-35, 2003. https://doi.org/10.1590/S1413-24782003000200003

GARCÉS, C. L. L; SILVA, C. T.; MORALES, E. N. (Orgs.). Desafiando Leviatãs: experiências indígenas com o desenvolvimento, o reconhecimento e os Estados. Belém: Editora do Museu Paraense Emílio Goeldi, 2019.

GAVAZZI, R. A. Agrofloresta e Cartografia Indígena: a gestão territorial e ambiental nas mãos dos Agentes Agroflorestais Indígenas do Acre. Dissertação de Mestrado. FFLCH-USP. São Paulo/SP, 2012.

GRUPIONI, L. D. B. Contextualizando o campo de formação de professores Indígenas no Brasil. In: GRUPIONI, L. D. B. (Org.). Formação de Professores Indígenas no Brasil: repensando trajetórias. Brasília/DF, 2006.

GRUPIONI, L.D.B. Olhar Longe, porque o futuro é longe: cultura, escola e professores indígenas no Brasil. Tese (Doutorado em Antropologia Social). São Paulo: Universidade de São Paulo, 2008.

LUCIANO, G. S. Educação para o manejo e domesticação do mundo: entre a escola ideal e a escola real: os dilemas da educação escolar indígena no alto Rio Negro. Tese (Doutorado em Antropologia). ICS/UNB. Brasília/DF, 2011.

LUCIANO, G. S. O índio brasileiro: o que você precisa saber sobre os povos indígenas no Brasil de hoje. Ministério de Educação, SECAD, 2006.

MAGALHÃES, M. P. (Orgs.). Amazônia Antropogênica. 1ed. Belém: Museu Paraense Emilio Goeldi, 2016.

MELIÁ, B. Educação Indígena e Alfabetização. São Paulo: Edições Loyola, 1979.

MELIÁ, B. Educação indígena na escola. Cadernos Cedes, v. 19, n. 49, p. 11-17, 1999. https://doi.org/10.1590/S0101-32621999000200002

OLIVEIRA, L. A; NASCIMENTO, R.G. Roteiro para uma história da educação escolar indígena: notas sobre a relação entre política indigenista e educacional. Educação \& Sociedade. vol.33 n.120 Campinas Jul./Set. 2012. https://doi.org/10.1590/S0101-73302012000300007

PONCE, A. Educação e Luta de Classes. Tradução de José Severo de Camargo Pereira. 24a Edição. São Paulo: Cortez, 2015.

RESENDE, M. M. S. El saber indígena, el saber geográfico y la ensenanza de la Geografia. Tese (Doutorado em Geografia Humana). Barcelona. Universidade de Barcelona/ESP, 1992.

RESENDE, M. M. S. Um mapa do que pode ser a Geografia nas Escolas Indígenas. Em Aberto. Brasília, ano 14, n.63, jul./set. 1994.

RIBEIRO, D. Cândido Mariano da Silva Rondon. Global Editora, 1 ed., 2017.

ROCHA, G. O. D. A Trajetória da disciplina Geografia no currículo escolar brasileiro (18371942). Dissertação (Mestrado em Educação), PUC/SP, 1996.

RODRIGUES, A. D. Línguas indígenas: 500 anos de descobertas e perdas. D.E.L.T.A., v. 9, n.1, p. 83-103. PUC/SP. São Paulo/SP, 1993.

SANTOS, H. N. R. Modos de Perceber e Representar o Ambiente e o Espaço no Ensino de Geografia Realizado por Professores Indígenas Tembé da Aldeia Cajueiro - Paragominas - PA. Dissertação (Mestrado em Antropologia). PPGA/UFPA, Belém/PA, 2017.

SCHADEN, E. Educação indígena. Problemas Brasileiros, v. 14, n. 152, p. 23-32, 1976.

SILVA, M. F. Interculturalidade no Curriculo da disciplina de ciências na Escola Indígena Tatakti Kyikatêjê: Possibilidades de realização de um projeto societário. Tese (Doutorado em Educação para a Ciência). Unesp, Bauru/SP, 2019.

SOUSA, E. M. M. Cartografia Histórico-Social do Povo Assurini do Trocará/PA. Trabalho de Conclusão de Curso (Licenciatura em Geografia). CCSE/UEPA, Belém/PA, 2018.

SOUZA, T. T; PEZZATO, J. P. A Geografia escolar: de 1549 até a década de 1960. In: GODOY, P. R. T. (Org.). História do pensamento geográfico e epistemologia em Geografia [online]. São Paulo: Cultura Acadêmica, 2010. 
SURUI, W. O mito de wyrating e mutum na produção de material didático para a Educação Infantil da escola Sawarapy Surui. Trabalho de Conclusão de Curso (Licenciatura Intercultural Indígena). UEPA. Marabá/PA 2016.

TASSINARI. A. M. A educação escolar indígena no contexto da antropologia brasileira. Ilha: Revista de Antropologia. v.10, n. 1 (2008). Universidade Federal de Santa Catarina - UFSC. p. 217-244. https://doi.org/10.5007/2175-8034.2008v10n1p217

UEPA. Projeto Político Pedagógico do curso de Licenciatura Intercultural Indígena. Belém: UEPA/PROGRAD/NUFI, 2016.

UFAM. Projeto Politico Pedagógico do curso de Formação de Professores Indígenas. Manaus: UFAM/PROEG, 2019.

UNIFAP. Projeto Político Pedagógico do curso de Licenciatura Intercultural Indígena. Oiapoque: UNIFAP/PROGRAD, 2019.

VESENTINI, J. W. O ensino da geografia na escola do século XXI. In: VESENTINI, J.W. Repensando a geografia escolar para o século XXI. São Paulo, Plêidade, 2009.

Recebido em: 05/03/2020

Aceito para publicação em: 14/08/2020 